\title{
Genetic variation of TLR-4, TLR-9 and TIRAP genes in Iranian malaria patients
}

Sedigheh Zakeri ${ }^{1 *}$, Sakineh Pirahmadi ${ }^{1,2}$, Akram A Mehrizi $^{1}$ and Navid D Djadid ${ }^{1}$

\begin{abstract}
Background: Toll-like receptors (TLRs) recognize pathogen-associated molecular patterns and their activation leads to the induction of effector genes involving inflammatory cytokines that may have contribute to controlling parasite growth and disease pathogenesis. The current immunogenetic study was designed to analyse the key components of innate immunity, TLRs and TIRAP (Toll-interleukin-1 receptor domain-containing adaptor protein), also known as MAL (MYD88 adaptor-like), in Iranian patients with mild malaria.

Methods: The t/r-4 (D299G and T399l), t/r-9 (T-1486C and T-1237C) and tirap (S180L) genes were assessed in 640 Baluchi individuals (320 Plasmodium falciparum-infected and 320 non-infected, median age of 28 years) from malaria-endemic regions using polymerase chain reaction-restriction fragment length polymorphism (PCR-RFLP) methods.

Results: Common t/r-4 SNPs and promoter SNPs of t/r-9 were distributed among $P$. falciparum-infected and noninfected groups $(P>0.05)$ that showed no association of these variants with mild clinical manifestation. The comparison of the tirap S180L genotypes between patients with mild malaria and those healthy individuals showed that the frequency of heterozygosity was significantly higher in infected than non-infected individuals (33.8 vs. 25.6; $O R, 1.479 ; 95 \% \mathrm{Cl}, 1.051-2.081 ; P=0.024$ ). The result also revealed a significant association of tirap S180L $(P<0.05)$ with development of mild malaria, which is common in Baluchi populations, who are living in malaria hypoendemic region of Iran but not in African populations (0\%-6\%).
\end{abstract}

Conclusion: These data point towards the need for addressing the exact role of TLRs in contributing to human genetic factors in malaria susceptibility/resistance/severity within different malaria settings in the world.

\section{Background}

In malaria, clinical manifestations are different among individuals who are infected with Plasmodium falciparum, ranging from asymptomatic infection to severe life-threatening forms. The development of severe malaria is due to the marked changes in cytokine expression that results in the individual's immune response to parasites. Indeed, the pathogenesis of severe malaria is complex and so far, the sequence of events leading to severe malaria is not completely known. To understand why some infections lead to severe forms of the disease, research has been focused on identifying

\footnotetext{
* Correspondence: zakeris@yahoo.com

'Malaria and Vector Research Group (MVRG), Biotechnology Research Center (BRC), Institut Pasteur Iran, Tehran, Iran, Pasteur Avenue, P.O.BOX

1316943551, Tehran, Iran

Full list of author information is available at the end of the article
}

parasite virulence phenotypes and the genetic make-up of the host [1].

Toll-like receptors (TLRs) have been defined as patternrecognition receptors whose function is to recognize pathogen-associated molecular patterns (PAMPs), including microbial pathogens, virulence factors and intracellular protozoan parasites [2-4]. The activation of TLRs leads to the induction of effector genes involving inflammatory cytokines and, as a result, provides links between innate and adaptive immunity [5]. In vitro and in vivo results showed that TLRs (TLR-2, TLR-4, and TLR-9) are central mediators of pro-inflammatory responses to Plasmodium infection [6-12]. The adaptor protein TIRAP (Tollinterleukin-1 receptor domain-containing adaptor protein), also known as MAL (MYD88 adaptor-like), mediates downstream signaling of TLR-2 and TLR-4 inducing pro-inflammatory responses [13].

\section{Biomed Central}


Single nucleotide polymorphisms (SNPs) have been described for $t l r-4, t l r-9$ and tirap genes that alter susceptibility to infectious and inflammatory diseases [14]. For $t l r-4$, the most extensively studied genetic variations are two frequently non-synonymous co-segregating SNPs (D299G/T399I) that change the ligand-binding site of the receptor [15]. tlr-4 polymorphisms are assumed to be correlated with risk of severe malaria as reported by Mockenhaupt and colleagues [7]. Two common tlr-9 promoter SNPs, T-1486C (rs1870884) and T1237C (rs5743836) are assumed to be associated with susceptibility to asthma [16] and placental malaria [8], respectively. The adaptor protein tirap S180L SNP (rs8177374) has been reported to diminish TLR-2 and TLR-4 signaling $[3,13]$ and heterozygosis for this SNP has been claimed to confer protection against mild and severe malaria to an extent comparable to HbAs [17].

Regarding the association between human gene polymorphism and disease, most studies for malaria susceptibility/resistance have been conducted on populations from Africa and south-east Asia. There is no information on malaria-associated gene polymorphisms from Iran, where malaria transmission is hypoendemic and there is no record of severe malaria and death due to this disease is rare. Up to this time, it is difficult to confirm the association between certain TLR polymorphisms and malaria susceptibility due to differences in ethnicity, location, environmental factors and exposure to infectious pathogen; hence, conducting different studies on various populations are needed to clarify this issue. Therefore, the current study was designed to look at the polymorphisms in $t l r-4$ and $t l r-9$ genes in Baluchi ethnic groups from south-eastern parts of Iran with unstable and hypoendemic malaria transmission. In addition, SNP in tirap, which is a common adaptor protein for TLR-2 and TLR-4, was assessed. Finally, the frequencies of the common SNPs, observed in $t$ lr-4, tlr-9 and tirap genes, among Baluchi patients with mild malaria and healthy control individuals were compared. The obtained results might enable us to understand the nature and outcome of the malaria disease in humans, and evaluate novel diagnostic and therapeutic strategies for this disease.

\section{Methods}

\section{Study areas and population}

Malaria is endemic in Sistan and Baluchistan Province (Iran), and the transmission is year-round with two peaks, the first from May to August with Plasmodium vivax as the predominant species and the second from October to November when both P. falciparum and $P$. vivax infections are usually recorded. In 2008, approximately 11,460 malaria cases were reported in Iran, $10 \%$ of which were microscopically diagnosed as
P. falciparum. Most of the cases (94\%) were recorded in the south-eastern provinces and in these regions; there is no report of severe malaria, anaemia or death due to malaria. Moreover, most patients were adults with uncomplicated malaria.

The study population was consisted of 640 Baluchi individuals (420 men and 220 women; median age of 28 years) from malaria endemic region of Sistan and Baluchistan Province. The patients $(\mathrm{n}=320)$ with febrile $P$. falciparum were recruited in an outpatient clinic at primary health centers in Chabahar district during April 2004-November 2009. These patients, who were presented with malaise, fever, or muscular pain and headache, were considered symptomatic and classified as having mild malaria (210 men and 110 women, median age of 28 years) and parasitaemia was ranged 1,000 to 35,000 asexual parasites $/ \mathrm{mm}^{3}$. All patients who were infected with $P$. falciparum had a fever and the diagnosis was confirmed via microscopy. Healthy Baluchi individuals ( $\mathrm{n}=320,205$ men and 115 women; median age of 27 years) with no history of febrile or malaria clinical symptoms were included as control. Nested PCR was used to confirm infection and also co-infection with $P$. vivax in both patient and control groups. After obtaining an informed consent from adults or the parents or legal guardians of children, $1 \mathrm{ml}$ of blood was collected from the individuals in vacuum EDTA tubes and stored at $-20^{\circ} \mathrm{C}$. All individuals with fever and confirmed malaria were treated according to the national guidelines. This study was approved by the Ethical Review Committee of Research in Pasteur Institute of Iran.

\section{Detection of parasites by nested-PCR assay}

Genomic DNA was isolated from whole blood collected in EDTA tubes, by using the commercially available DNA purification kit (Promega, Madison, WI, USA), and kept at $-20^{\circ} \mathrm{C}$ until use. DNA of Plasmodium species ( $P$. vivax and $P$. falciparum) was detected by nested-PCR amplification of the small sub-unit ribosomal ribonucleic acid (18ssrRNA) genes using the primers and cycling parameters described previously [18]. The amplified products were resolved by $2 \%-2.5 \%$ agarose gel electrophoresis and stained with ethidium bromide for visual detection by ultraviolet transillumination.

\section{Genotyping and SNPs detection by PCR-RFLP}

The non-synonymous SNPs of $t l r-4$ D299G and T399I, the two promoter SNPs of $t l r-9$ at positions T-1486C and T-1237C as well as tirap S180L SNPs were studied. The different SNPs were identified by PCR-RFLP analysis. The primers, PCR cycling conditions and RFLP are shown in Table 1. All amplifications were carried out in a final volume of $25 \mu \mathrm{L}$ including $1 \mu \mathrm{L}$ of template 
Table 1 Primers and profiles used for PCR-RFLP of the t/r-4, t/r-9 and tirap genes

\begin{tabular}{|c|c|c|c|c|c|c|c|c|c|}
\hline \multirow[b]{2}{*}{ Genes } & \multirow[b]{2}{*}{ Primer } & \multirow[b]{2}{*}{ Sequence } & \multicolumn{4}{|c|}{$\begin{array}{c}\text { Temperature }{ }^{\circ} \mathrm{C} / \\
\text { time }(\mathrm{min})\end{array}$} & \multirow[b]{2}{*}{$\begin{array}{l}\text { Product } \\
\text { size (bp) }\end{array}$} & \multirow[b]{2}{*}{ Restriction Enzyme } & \multirow[b]{2}{*}{ Cut Product Size (bp) } \\
\hline & & & A & $E$ & D & C & & & \\
\hline & 299TLR4F & ATACTTAGACTACTACCTCC_ATG & $\begin{array}{l}56 \\
(1)\end{array}$ & $\begin{array}{l}72 \\
(1)\end{array}$ & $\begin{array}{l}94 \\
(1)\end{array}$ & 35 & 213 & Ncol (Fermentase) & G: $19+194$ \\
\hline \multirow[t]{4}{*}{$t / r-4^{*}$} & 299TLR4R & TTGTTGGAAGTGAAAGTAAG & & & & & & & \\
\hline & 399TLR4F & TGTTATCAAAGTGATTTTGGGAGAA & $\begin{array}{l}54 \\
(1)\end{array}$ & $\begin{array}{l}65 \\
(1)\end{array}$ & $\begin{array}{l}94 \\
(1)\end{array}$ & 35 & 185 & Hinf I (Fermentase) & I: $162+23$ \\
\hline & 399TLR4R & AGGTAAATGAGGTTTCTGAGTGATAGG & & & & & & & \\
\hline & -1237TLR9F & TTCATTCAGCCTTCACTCAG & & & & & & & T: $264+145+126+23$ \\
\hline \multirow[t]{4}{*}{$t / r-9$} & -1237 TLR9R & TCAAAGCCACAGTCCACAG & $\begin{array}{l}64 \\
(1)\end{array}$ & $\begin{array}{l}72 \\
(1)\end{array}$ & $\begin{array}{l}94 \\
(1)\end{array}$ & 30 & 558 & Bsll (Fermentase) & C: $264+115+126+30+23$ \\
\hline & -1486TLR9F & TTCATTCAGCCTTCACTCAG & $\begin{array}{l}64 \\
(1)\end{array}$ & $\begin{array}{l}72 \\
(1)\end{array}$ & $\begin{array}{l}94 \\
(1)\end{array}$ & 30 & 558 & AfIII (Fermentase) & $\mathrm{T}: 413+145$ \\
\hline & -1486 TLR9R & TCAAAGCCACAGTCCACAG & & & & & & & \\
\hline & 180 TIRAP $\mathrm{F}$ & AGTGCTGTACCATCGACCTGCTG & & & & & & & \\
\hline tirap ** & 180 TIRAP $\mathbf{R}$ & TTCCCCTTCTCCCTCCTGTAGTAG & $\begin{array}{l}60 \\
(1)\end{array}$ & $\begin{array}{l}72 \\
(1)\end{array}$ & $\begin{array}{l}94 \\
(1)\end{array}$ & 35 & 161 & Eam1105I (Fermentase) & S: $141+20$ \\
\hline
\end{tabular}

All primers described in this study were designed in our laboratory (GenBank accession no. AF177765.1 for t/r-4; NW-001838877.2 for t/r-9 and NT-033899.7 for tirap) except 299TLR4F primer that was described previously [26]. The bold and underline nucleotides located in the 3 ' of forward primers indicate a mutation, and create a restriction site accordingly.

A: Annealing, E: Extension, D: Denaturation, C: No. of cycles.

* trr-4 (gat) D299G (ggt).

* trr-4 (acc) T399l (atc).

** tirap (tcg) S180L (ttg).

genomic DNA. The primers were used at a final concentration of $250 \mathrm{nM}$ and the reaction mixture contained $10 \mathrm{mM}$ Tris- $\mathrm{HCl}$ (pH 8.3), $50 \mathrm{mM} \mathrm{KCl,} 2 \mathrm{mM}$ $\mathrm{MgCl}_{2}$, each of the four deoxynucleotide triphosphates at a concentration of $125 \mu \mathrm{M}$, and $0.2 \mathrm{U}$ of Taq polymerase (Invitrogen, Carlsbad, CA). The DNA fragments, obtained following PCR amplification or RFLP analysis, were electrophoresed on $2 \%$ to $3 \%$ agarose gels (Invitrogen, Carlsbad, CA), respectively.

\section{DNA sequence analysis}

To verify the results obtained by RFLP, all PCR products were sequenced for $t l r-4, t l r-9$ and tirap genes using the primers described in Table 1 . Therefore, the amplified fragments were gel-purified using the QIAquick Gel Extraction kit (Qiagen, Hilden, Germany) following the manufacturer's instructions. Direct sequencing of the DNA fragments was performed in both directions for each PCR product using the dideoxy chain termination procedure (Chemistry V3.1, Applied Biosystems) and also the 3730XL DNA analyser (Applied Biosystems) by MilleGen sequencing service (Labege, France).

\section{Statistical analysis}

The sample size was calculated using OpenEpi software [19], with $80 \%$ power and $95 \%$ confidence level. Allele and genotype frequencies were calculated for different genes by direct counting. The comparison of the allele and genotype frequencies of the study groups was determined by $X^{2}$ test using SPSS for windows (version 16.0) and $P<0.05$ was considered to be significant. To determine if genetic variation in $t l r-4, t l r-9$ and tirap genes were associated with risk of developing malaria, odds ratios (OR) and 95\% confidence intervals (CIs) were calculated. The Hardy-Weinberg Equilibrium (HWE) was performed by comparing the observed numbers of different genotypes with those expected under the HWE for the estimated genotype frequencies [20] and $P>$ 0.05 was in HWE. Genotypic deviations from HWE were assessed using Pearson's chi-square $\left(X^{2}\right)$ statistical test.

\section{Results}

Based on nested-PCR results, a total of 320 patients with mild malaria were shown to be infected with $P$. falciparum, as a mono-infection, and none of the healthy control individuals had either $P$. falciparum or $P$. vivax infections.

\section{tIr-4, t/r-9 and tirap polymorphisms}

Overall, $P$. falciparum-infected $(\mathrm{n}=320)$ and noninfected $(\mathrm{n}=320)$ Baluchi individuals were successfully analysed for the $t l r-4, t l r-9$ and tirap SNPs by PCRRFLP methods and the sequencing data confirmed RFLP results. To determine whether there was any frequency difference in the allele (Table 2) and genotype (Table 3) 
Table 2 Allele frequencies for the t/r-4, t/r-9 and tirap polymorphisms in $P$. falciparum-infected and noninfected subjects

\begin{tabular}{|c|c|c|c|c|c|c|}
\hline \multirow{2}{*}{\multicolumn{2}{|c|}{$\begin{array}{c}\text { Gene } \\
\text { (Polymorphism) }\end{array}$}} & \multicolumn{4}{|c|}{ Allele frequency } & \multirow{3}{*}{$P$ value } \\
\hline & & \multicolumn{2}{|c|}{ Non-infected } & \multicolumn{2}{|c|}{ Infected } & \\
\hline & & w & $M$ & w & $M$ & \\
\hline \multirow[t]{2}{*}{$t / r-4$} & D299G & 0.948 & 0.052 & 0.923 & 0.077 & 0.068 \\
\hline & T399I & 0.921 & 0.079 & 0.923 & 0.077 & 0.835 \\
\hline \multirow[t]{2}{*}{$t / r-9$} & -1486 & 0.651 & 0.349 & 0.646 & 0.354 & 0.815 \\
\hline & -1237 & 0.898 & 0.102 & 0.923 & 0.077 & 0.116 \\
\hline tirap & S180L & 0.862 & 0.138 & 0.825 & 0.175 & 0.065 \\
\hline
\end{tabular}

$\mathrm{W}=$ wild allele.

$\mathrm{M}=$ mutant allele. prevalence for each SNP, a comparison was made between the two studied groups. All examined SNPs were presented in studied populations at different frequencies. The frequencies for two polymorphic alleles in $t l r-4$ (D299G and T399I) and tlr-9 (T-1237C) were less than $10 \%$ and those for polymorphic alleles in tlr-9 $(\mathrm{T}-1486 \mathrm{C})$ and tirap (S180L) were greater than 10\% (Table 2) in infected patients. Furthermore, there were no significant differences in all examined SNPs frequencies among Baluchi patients with mild malaria and related case controls $(P>0.05$, Table 2$)$.

\section{Frequencies of $t / r-4, t / r-9$ and tirap genotypes}

The three genotypes of $t l r-4$ D299G were present in Baluchi infected individuals, but $t l r-4$ G299G

Table 3 Genotype frequencies for the $t / r-4, t / r-9$ and tirap polymorphisms in $P$. falciparum-infected and non-infected subjects

\begin{tabular}{|c|c|c|c|c|c|c|c|c|c|}
\hline \multirow{2}{*}{\multicolumn{2}{|c|}{$\begin{array}{c}\text { Gene } \\
\text { (Polymorphism) }\end{array}$}} & \multicolumn{5}{|c|}{ Genotype Frequency } & \multirow{3}{*}{$\begin{array}{c}P \\
\left(\mathrm{HWE}, X^{2}\right)\end{array}$} & \multirow{3}{*}{$\begin{array}{c}\text { OR } \\
(95 \% \mathrm{Cl})\end{array}$} & \multirow{3}{*}{$\begin{array}{c}P \\
\text { value }\end{array}$} \\
\hline & & \multicolumn{3}{|c|}{ Observed } & \multicolumn{2}{|c|}{ expected } & & & \\
\hline & & Genotype & $\begin{array}{c}\text { Non-infected No } \\
(\%)\end{array}$ & $\begin{array}{c}\text { Infected No } \\
(\%)\end{array}$ & $\begin{array}{c}\text { Non-infected No } \\
(\%)\end{array}$ & $\begin{array}{c}\text { Infected No } \\
(\%)\end{array}$ & & & \\
\hline & & W (D/D) & $287(89.7)$ & $276(86.3)$ & $288(90)$ & $273(85.3)$ & & $\begin{array}{c}0.721 \\
(0.446-1.166)\end{array}$ & 0.181 \\
\hline & D299G & $\mathrm{H}(\mathrm{D} / \mathrm{G})$ & $33(10.3)$ & $39(12.1)$ & $31(9.7)$ & $45(14.1)$ & $\begin{array}{l}\mathrm{NI}=0.33 \\
\mathrm{I}=0.013\end{array}$ & $\begin{array}{c}1.161 \\
(0.709-1.899)\end{array}$ & 0.553 \\
\hline \multirow[t]{6}{*}{$t / r-4$} & & $M(G G)$ & - & $5(1.6)$ & $1(0.3)$ & $2(0.6)$ & & - & - \\
\hline & & W (T/T) & $270(84.4)$ & $271(84.7)$ & $272(85)$ & $273(85.3)$ & & $\begin{array}{c}1.024 \\
(0.667-1.572)\end{array}$ & 0.913 \\
\hline & T399l & $H(T / l)$ & $50(15.6)$ & $49(15.3)$ & $46(14.4)$ & $45(14.1)$ & $\begin{array}{c}\mathrm{NI}=0.125 \\
\mathrm{I}=0.138\end{array}$ & $\begin{array}{c}0.976 \\
(0.636-1.499)\end{array}$ & 0.913 \\
\hline & & $M(I / I)$ & - & - & $2(0.6)$ & $2(0.6)$ & & - & - \\
\hline & & $W(T T)$ & $130(40.6)$ & $142(44.4)$ & $136(42.5)$ & $133(41.6)$ & & $\begin{array}{c}1.166 \\
(0.852-1.596)\end{array}$ & 0.337 \\
\hline & $\mathrm{T}-1486 \mathrm{C}$ & $\mathrm{H}(\mathrm{TC})$ & $157(49.1)$ & $130(40.6)$ & $145(45.3)$ & $147(45.9)$ & $\begin{array}{c}\mathrm{NI}=0.149 \\
I=0.058\end{array}$ & $\begin{array}{c}0.710 \\
(0.520-0.971)\end{array}$ & 0.032 \\
\hline \multirow[t]{5}{*}{$t / r-9$} & & $M(C C)$ & $33(10.3)$ & $48(15)$ & $39(12.2)$ & $40(12.5)$ & & $\begin{array}{c}1.535 \\
(0.956-2.464)\end{array}$ & 0.075 \\
\hline & & W (TT) & $270(84.4)$ & $276(86.2)$ & 258 (80.6) & $273(85.3)$ & & $\begin{array}{c}1.162 \\
(0.749-1.801)\end{array}$ & 0.503 \\
\hline & $\mathrm{T}-1237 \mathrm{C}$ & $\mathrm{H}(\mathrm{TC})$ & $35(10.9)$ & $39(12.2)$ & $59(18.4)$ & $45(14.1)$ & $\begin{array}{l}\mathrm{NI}<0.0001 \\
\mathrm{I}=0.0135\end{array}$ & $\begin{array}{c}1.130 \\
(0.696-1.836)\end{array}$ & 0.621 \\
\hline & & $M(C C)$ & $15(4.7)$ & $5(1.6)$ & $3(1)$ & $2(0.6)$ & & $\begin{array}{c}0.323 \\
(0.116-0.899)\end{array}$ & 0.023 \\
\hline & & W (S/S) & $235(73.4)$ & $210(65.6)$ & $238(74.4)$ & $218(68.1)$ & & $\begin{array}{c}0.691 \\
(0.492-0.969)\end{array}$ & 0.032 \\
\hline \multirow[t]{2}{*}{ tirap } & S180L & $H(S / L)$ & $82(25.6)$ & $108(33.8)$ & 76 (23.7) & $92(28.8)$ & $\begin{array}{l}\mathrm{NI}=0.150 \\
\mathrm{I}=0.0025\end{array}$ & $\begin{array}{c}1.479 \\
(1.051-2.081)\end{array}$ & 0.024 \\
\hline & & $M(L / L)$ & $3(1)$ & $2(0.6)$ & $6(1.9)$ & $10(3.1)$ & & $0.665(0.11-4.004)$ & 0.653 \\
\hline
\end{tabular}

Nl: non-infected.

I: P. falciparum-infected.

HWE: Hardy-Weinberg Equilibrium $(P<0.05)$.

W: Wild type allele, H: Heterozygote allele, M: Mutant type allele.

OR: Odds ratios.

Cl: Confidence interval. 
homozygosity was absent in Baluchi healthy individuals (Table 3) that might suggest an association of this genotype with mild malaria clinical symptoms $(1.6 \%$, $P=0.025)$. In addition, two genotypes of $t l r-4$ T399T and $t t-4$ T399I were observed among cases and controls with no significant difference $(P>0.05)$. tlr-4 I399I homozygous was absent in both studied groups (Table 3 ). The comparison of the tlr-9 T-1237C and T-1486C genotypes between patients with mild malaria and those healthy individuals showed that the three tlr-9 T-1237C and $\mathrm{T}-1486 \mathrm{C}$ genotypes were present among both studied groups (Table 3). Heterozygosity for $t l r-9 \mathrm{~T}-1486 \mathrm{C}$ was more prevalent among case controls $(49.1 \%)$ than among malaria patients (40.6\%, Table 3). tlr-9 C-1486C homozygote was also found in both $P$. falciparuminfected (15\%) and non-infected cases (10.3\%) with no statistically significant $(P>0.05)$. Furthermore, $t l r-9$ $\mathrm{T}-1237 \mathrm{C}$ frequency was low in the cases $(1.6 \%)$ and controls $(4.7 \%)$. The comparison of the tirap S180L genotypes between patients with mild malaria and those healthy individuals showed that the frequency of heterozygosity was significantly higher in infected than noninfected individuals (33.8 vs. 25.6; OR, 1.479; $95 \% \mathrm{CI}$, $1.051-2.081 ; P=0.024$ ) (Table 3 ).

\section{Discussion}

Severe malaria accounts for many of deaths due to the infection with P. falciparum. Areas of intense malaria transmission such as African countries tend to have a greater proportion of severe cases, whereas the opposite is seen in areas of lower transmission [21]. Additionally, in some other malaria endemic regions of the world, including Iran, the severe cases are very rare. This, in turn, raises the question of why small subset of $P$. falciparum-infected individuals develops the severe and complicated disease but, others develop a mild and uncomplicated disease or remain asymptomatic. To verify and provide further data on this issue, different studies showed the contribution of host genetic factors to the severe outcome following infection [22] and since then, several genes have been shown to be involved in protection or susceptibility to severe malaria including TLRs that play an important role in innate immunity [23].

Mockenhaupt and co-workers [7] investigated $t l r-2$, $t l r-4$ and $t l r-9$ polymorphisms in African children. They found that a common $t l r-4$ D299G increases the risk of severe paediatric malaria without affecting on the risk of infection. However, in the present study, $10 \%$ of the participants in both groups had less than 15 years old with no sign of severe disease. In addition, in both studied groups, the frequency of $t l r-4$ D299G was low and similar. Therefore, this result suggested that more studies on different populations from malaria endemic regions with various endemicity are needed to draw final conclusion on the role of $t l r-4$ D299G and its association with malaria manifestation. On the other hand, study by Mockenhaupt and colleagues [7] showed that $t l r-4$ T399I predisposes to severe malaria with symptoms such as severe anaemia and respiratory distress. This suggests that $t l r-4$ might be involved in P. falciparum recognition and host responses in humans, and that tlr-4 could contribute to the control of the infection. However, in this study, tlr-4 T399I genotype has been observed in malaria patients and healthy individuals with no statistically significant that showed no association of this genotype with mild clinical manifestation.

In the next step, the frequency of promoter polymorphisms of tlr-9 was assessed in target population. tlr-9 T-1486C heterozygote and homozygote were found in both P. falciparum-infected and non-infected cases, with no association with mild malaria, which was in line with other findings [7,24]. Furthermore, tlr-9 T-1237C frequency was low in the cases and controls with no association with mild malaria. To date, the functional roles of this promoter SNP and of T-1486C are unclear, but our data argues against a major role of these polymorphisms in malaria manifestations.

Study by Khor and colleagues [17] in Gambia, Kenya and Vietnam revealed that tirap S180L heterozygosity was associated with a significant protective effect against both mild and severe malaria. In addition, study by Leoratti and co-workers [24] in Brazilian populations showed that no association of this genotype was found with mild malaria. In contrast, in the present study, there was a high frequency of heterozygosity (tirap S180L) in Baluchi infected individuals than controls (33.8\% vs. $25.6 \%)$. The comparison of healthy and infected individuals showed that the risk of mild malaria was increased 1.5-fold in individuals with tirap S180L (OR, 1.479; 95\% CI, 1.051-2.081, $P=0.024$ ). It is worth mentioning that the frequency of this heterozygosity was higher among Iranian infected patients with P. falciparum (33.8\%), who are living in malaria hypoendemic areas (present study), than Ghanan, Gambian, Kenyan and Vietnamese populations (0\%-3.5\%) with reported severe cases of malaria $[25,17]$. In fact, the presence of the high frequency of tirap S180L variant in Iranian malaria patients with mild malaria might support the role of this SNP in protection against severe malaria by intermediate levels of pathway activation and balanced inflammatory response (by attenuates TLR-2 and TLR-4 signaling pathways).

Moreover, homozygous tirap L180L was found in both infected and non-infected Baluchi individuals $(0.6 \%$ vs. $1 \%)$, which was not reported in African and Vietnamese populations, where malaria is highly endemic. The rarity of the mutant allele in African populations might be 
related with high mortality rate in these populations due to malaria, thus this may strongly reduce the frequency of tirap L180L genotype in these regions. This homozygousity suggested to be a risk factor for several diseases, including malaria [25], which is in contrast with the present finding (OR, 0.665; 95\% CI, 0.11-4.004; $P=0.653$ ). The specific role of tirap L180L on malaria disease processes needs further investigation in different ethnic groups.

Overall, wild-type homozygosity for all three examined genes was predominant among patients with mild malaria and healthy control groups. Statistical analysis also showed that all of SNPs were in HWE in the control group except for $t l r-9 \mathrm{~T}-1237 \mathrm{C}$. In addition, the observed genotype frequencies in the patients with mild malaria were significantly different from the expected frequencies for $t l r-4$ D299G, tlr-9 T-1237C and tirap S180L SNPs, which are deviated from HWE. This could be explained by genetic drift, non-random mating or an indication of selection acting on specific genotype and at the present, there is no any evidence to prove any of them in this population.

\section{Conclusion}

In summary, in the current immunogenetic study, it seems that the role of TLR polymorphisms is varying in different ethnic groups from different malaria endemicity. High frequency of heterozygous tirap S180L in malaria infected individuals point to the role of this genotype as a risk factor for the development of mild malaria, but protect from severe malaria. Comparing these data with previously reported results from other malaria endemic regions $[17,25]$ suggests a need for addressing the exact role of TLRs and TIRAP in contributing to human genetic factors in malaria susceptibility/resistance/severity within different malaria transmission settings and manifestation pattern in the world.

\section{Acknowledgements \\ We are grateful for the hospitality and generous collaboration of Zahedan University of Medical Sciences, staff in Public Health Department, Sistan and Baluchistan Province and Chabahar District for their assistance in collection of human blood samples. We are indebted to the individuals and their families in Sistan and Baluchistan Province for their willingness to participate in this study. We also thank to Dr. A. Fotouhi, Dr. A.A. Haghdoost and Dr. E. Mostafavi for assistance in statistical analysis and critical reading of the manuscript. This work was financially supported by Institut Pasteur Iran.}

\section{Author details}

${ }^{1}$ Malaria and Vector Research Group (MVRG), Biotechnology Research Center (BRC), Institut Pasteur Iran, Tehran, Iran, Pasteur Avenue, P.O.BOX 1316943551, Tehran, Iran. 'Biology Department, Khatam University, Tehran, Iran.

\section{Authors' contributions}

$\mathrm{SZ}^{*}$ designed the work, supervised the study, analysed the data and wrote the manuscript. SP carried out polymorphism studies. AAM contributed in the analysis of the data. NDD participated in sample collection, helped with the sequence data analysis and also critical reading of the manuscript. All authors read and approved final manuscript and agree to submission.

\section{Competing interests}

The authors declare that they have no competing interests.

Received: 8 November 2010 Accepted: 4 April 2011

Published: 4 April 2011

References

1. Arbour NC, Lorenz E, Schutte BC, Zabner J, Kline JN, Jones M, Frees K, Watt JL, Schwartz : TLR4 mutations are associated with endotoxin hyporesponsiveness in humans. Nat Genet 2000, 25:187-191.

2. Medzhitov R: Toll-like receptors and innate immunity. Nat Rev Immunol 2001, 1:135-145

3. Akira S, Takeda K: Toll-like receptor signaling. Nat Rev Immunol 2004 , 4:499-511.

4. Gazzinelli RT, Ropert C, Campos MA: Role of the Toll/interleukin-1 receptor signaling pathway in host resistance and pathogenesis during infection with protozoan parasites. Immunol Rev 2004, 201:9-25.

5. Hoebe $K$, Janssen $E$, Beutler $B$ : The interface between innate and adaptive immunity. Nat Immunol 2004, 5:971-974.

6. Krishnegowda G, Hajjar AM, Zhu J, Douglass EJ, Uematsu S, Akira S, Woods AS, Gowda DC: Induction of proinflammatory responses in macrophages by the glycosylphosphatidylinositols of Plasmodium falciparum: cell signaling receptors, glycosylphosphatidylinositol (GPI) structural requirement, and regulation of GPI activity. J Biol Chem 2005, 280:8606-8616.

7. Mockenhaupt FP, Cramer JP, Hamann L, Stegemann MS, Eckert J, Oh NR, Otchwemah RN, Dietz E, Ehrhardt S, Schröder NW, Bienzle U, Schumann RR: Toll-like receptor (TLR) polymorphisms in African children: Common TLR4 variants predispose to severe malaria. J Commun Dis 2006, 38:230-245.

8. Mockenhaupt FP, Hamann L, von Gaertner C, Bedu-Addo G, von Kleinsorgen C, Schumann RR, Bienzle U: Common polymorphisms of tolllike receptors 4 and 9 are associated with the clinical manifestation of malaria during pregnancy. J Infect Dis 2006, 194:184-188.

9. Coban C, Ishii KJ, Uematsu S, Arisue N, Sato S, Yamamoto M, Kawai T, Takeuchi O, Hisaeda H, Horii T, Akira S: Pathological role of Toll-like receptor signaling in cerebral malaria. Int Immunol 2007, 19:67-79.

10. McCall MB, Netea MG, Hermsen CC, Jansen T, Jacobs L, Golenbock D, van der Ven AJ, Sauerwein RW: Plasmodium falciparum infection causes proinflammatory priming of human TLR responses. J Immunol 2007 179:162-171.

11. Parroche $P$, Lauw FN, Goutagny N, Latz E, Monks BG, Visintin A, Halmen KA, Lamphier M, Olivier M, Bartholomeu DC, Gazzinelli RT, Golenbock DT: Malaria hemozoin is immunologically inert but radically enhances innate responses by presenting malaria DNA to Toll-like receptor 9. Proc Natl Acad Sci USA 2007, 104:1919-1924.

12. Schumann RR: Malarial fever: hemozoin is involved but Toll-free. Proc Natl Acad Sci USA 2007, 104:1743-1744.

13. Yamamoto M, Sato S, Hemmi H, Sanjo H, Uematsu S, Kaisho T, Hoshino K, Takeuchi O, Kobayashi M, Fujita T, Takeda K, Akira S: Essential role for TIRAP in activation of the signaling cascade shared by TLR2 and TLR4. Nature 2002, 420:324-329.

14. Schroder NW, Schumann RR: Single nucleotide polymorphisms of Toll-like receptors and susceptibility to infectious disease. Lancet Infect Dis 2005 , 5:156-164

15. Rallabhandi P, Bell J, Boukhvalova MS, Medvedev A, Lorenz E, Arditi M, Hemming VG, Blanco JC, Segal DM, Vogel SN: Analysis of TLR4 polymorphic variants: new insights into TLR4/MD-2/CD14 stoichiometry, structure, and signaling. J Immunol 2006, 177:322-332

16. Lazarus R, Klimecki WT, Raby BA, Vercelli D, Palmer L, Kwiatkowski DJ, Silverman EK, Martinez F, Weiss ST: Single-nucleotide polymorphisms in the Toll-like receptor 9 gene (TLR9): frequencies, pairwise linkage disequilibrium, and haplotypes in three U.S. ethnic groups and exploratory case-control disease association studies. Genomics 2003 81:85-91.

17. Khor CC, Chapman SJ, Vannberg FO, Dunne A, Murphy C, Ling EY, Frodsham AJ, Walley AJ, Kyrieleis O, Khan A, Aucan C, Segal S, Moore CE, Knox K, Campbell SJ, Lienhardt C, Scott A, Aaby P, Sow OY, Grignani RT, 
Sillah J, Sirugo G, Peshu N, Williams TN, Maitland K, Davies RJ,

Kwiatkowski DP, Day NP, Yala D, Crook DW, Marsh K, Berkley JA, O'Neill LA,

Hill AV: A Mal functional variant is associated with protection against invasive pneumococcal disease, bacteremia, malaria and tuberculosis. Nat Genet 2007, 39:523-528.

18. Snounou G, Viriyakosol S, Zhu XP, Jarra W, Pinheiro L, do Rosario VE, Thaithong S, Brown KN: High sensitivity of detection of human malaria parasites by the use of nested polymerase chain reaction. Mol Biochem Parasitol 1993, 61:315-320.

19. Dean AG, Sullivan KM, Soe MM: Open Source Epidemiologic Statistics for Public Health, Version. [http://www.openepi.com], Updated 2009/20/05, accessed 2010/06/16.

20. Michael C: A simple calculator to determine whether observed genotype frequencies are consistent with Hardy-Weinberg equilibrium. 2008 [http://www.tufts.edu/ mcourt01/Documents/Court lab - HW calculator.xls].

21. Marsh K, Snow RW: Malaria transmission and morbidity. Parassitologia 1999, 41:241-246.

22. Haldane JBS: Disease and evolution. Ric Sci 1949, 19:68-76.

23. Akira S, Uematsu S, Takeuchi O: Pathogen recognition and innate immunity. Cell 2006, 124:783-801.

24. Leoratti FM, Farias L, Alves FP, Suarez-Mútis MC, Coura JR, Kalil J, Camargo EP, Moraes SL, Ramasawmy R: Variants in the Toll-like receptor signaling pathway and clinical outcomes of malaria. J Infect Dis 2008, 198:772-780.

25. Hamann L, Kumpf O, Schuring RP, Alpsoy E, Bedu-Addo G, Bienzle U, Oskam L, Mockenhaupt FP, Schumann RR: Low frequency of the TIRAP S180L polymorphism in Africa, and its potential role in malaria, sepsis, and leprosy. BMC Med Genet 2009, 10:65-70.

26. Van der Graaf CA, Netea MG, Morré SA, Heijer MD, Verweij PE, Van der Meer JW, Kullberg BJ: Toll-like receptor 4 Asp299Gly/Thr399lle polymorphisms are a risk factor for Candida bloodstream infection. Eur Cytokine Netw 2006, 17:29-34.

doi:10.1186/1475-2875-10-77

Cite this article as: Zakeri et al:: Genetic variation of TLR-4, TLR-9 and

TIRAP genes in Iranian malaria patients. Malaria Journal 2011 10:77.

\section{Submit your next manuscript to BioMed Central and take full advantage of:}

- Convenient online submission

- Thorough peer review

- No space constraints or color figure charges

- Immediate publication on acceptance

- Inclusion in PubMed, CAS, Scopus and Google Scholar

- Research which is freely available for redistribution

Submit your manuscript at www.biomedcentral.com/submit 